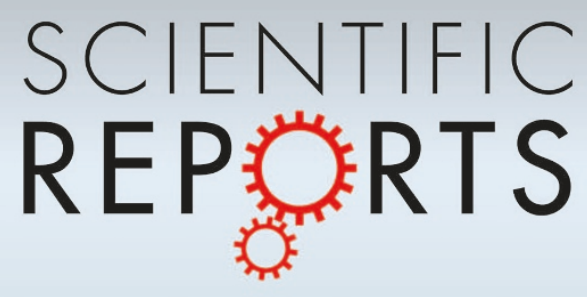

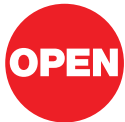

SUBJECT AREAS:

ENGINEERING

MATERIALS CHEMISTRY

METHODS

POLYMERS AND SOFT MATERIALS

Received

13 April 2012

Accepted

7 June 2012

Published

28 June 2012

Correspondence and requests for materials should be addressed to P.M.A. lajayan@rice.

edu)

\section{Paintable Battery}

\author{
Neelam Singh', Charudatta Galande', Andrea Miranda' , Akshay Mathkar', Wei Gao², \\ Arava Leela Mohana Reddy' , Alexandru Vlad ${ }^{1,3}$ \& Pulickel M. Ajayan ${ }^{1,2}$
}

\footnotetext{
'Department of Mechanical Engineering and Materials Science, Rice University, Houston, TX-77005, ${ }^{2}$ Department of Chemistry, Rice University, Houston, TX-77005, ${ }^{3}$ Institute of Information and communication Technologies, Electronics and Applied Mathematics, Electrical Engineering, Université catholique de Louvain, Louvain la Neuve, B-1348 Belgium.
}

If the components of a battery, including electrodes, separator, electrolyte and the current collectors can be designed as paints and applied sequentially to build a complete battery, on any arbitrary surface, it would have significant impact on the design, implementation and integration of energy storage devices. Here, we establish a paradigm change in battery assembly by fabricating rechargeable Li-ion batteries solely by multi-step spray painting of its components on a variety of materials such as metals, glass, glazed ceramics and flexible polymer substrates. We also demonstrate the possibility of interconnected modular spray painted battery units to be coupled to energy conversion devices such as solar cells, with possibilities of building standalone energy capture-storage hybrid devices in different configurations.

i-ion batteries power most of our portable electronics by virtue of their high energy and power density. Commercial Li-ion batteries are multilayer devices, fabricated by tightly rolling up sandwiched battery - components and packaging them into metal canisters ${ }^{1}$. Although Li-ion battery packs are compact and volumetrically efficient, the 'jellyroll' (Fig. 1a) design strategy limits the batteries to rectangular or cylindrical shapes, which constrains the form factors of devices. Recent efforts on unconventional battery designs have worked towards developing battery technologies that can be inconspicuously accommodated into devices and applications without constraining their form factors ${ }^{2}$. Some examples are thin and flexible batteries ${ }^{3,4}$, stretchable textile energy storage ${ }^{5,6}$, paper batteries ${ }^{7}$, microbatteries ${ }^{8}$ and transparent batteries ${ }^{9}$. However, a seamless integration of these energy storage systems into electronic devices and household objects remains a challenge. The advent of smart devices/objects has further generated interest in self-powered electronics ${ }^{10,11}$ with integrated storage. Such energy conversion-storage hybrids will require batteries that can be integrated directly into the object or surface of choice as well as with energy harvesting devices. Printing (or generally, painting) is already considered a viable technique for large-area fabrication of electronic devices (circuits, photovoltaics, displays, etc.) on virtually any type of substrate ${ }^{12}$. Consequently, there is huge interest in developing a fully paintable energy storage technology. Here we present a paradigm change in battery design and integration. We have developed a fully paintable Li-ion battery that can be simultaneously fabricated and integrated with commonly encountered materials and objects of daily use. Energy harvesting devices, such as solar cells, can then be easily integrated with these batteries to give any surface a standalone energy capture and storage capability. We could easily integrate this technology into standard construction materials (ceramic tiles), common household objects (ceramic mug), stainless steel as well as flexible polymer sheets.

\section{Results}

We adopted spray-painting technique to assemble batteries (Fig. 1b) due to advantages such as ease of operation and flexibility in formulation from small-scale (aerosol cans) to industrial scale systems (spray guns). Fabrication of batteries by spray painting requires formulation of component materials into liquid dispersions (paints), which can be sequentially coated on substrates to achieve the multilayer battery configuration. Commercial Li-ion batteries have positive and negative electrode materials coated on appropriate current collectors, sandwiching an ion conducting separator (Fig. 1a). Aluminum and copper foils are commonly used current collectors (CC) (positive and negative CC respectively), while electrode materials and separators are chosen based on desired voltage, current capacity, operating temperature and safety considerations ${ }^{13-15}$. We chose Lithium Cobalt Oxide [ $\left.\mathrm{LiCoO}_{2}\right]$ (LCO, positive electrode) and Lithium Titanium Oxide [ $\left.\mathrm{Li}_{4} \mathrm{Ti}_{5} \mathrm{O}_{12}\right]$ (LTO, negative electrode), for which the effective cell voltage is $\sim 2.5 \mathrm{~V}^{16}$. Graphite anode or high voltage cathodes could be used to increase the nominal voltage of paintable batteries $(\sim 3.6 \mathrm{~V}$ for LCO-Graphite cell). However, graphite based Li-ion batteries have safety concerns ${ }^{14,17}$ and LTO was chosen to ensure safer operation due to minimal risk of Li-metal 

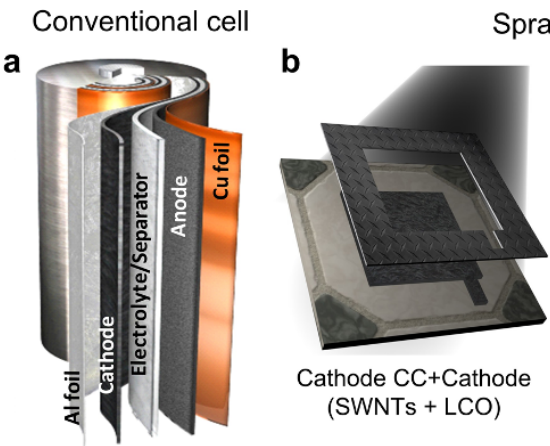

Spray painted battery assembly

Figure $1 \mid$ Paintable battery concept. (a) Simplified view of a conventional Li-ion battery, a multilayer device assembled by tightly wound 'jellyroll' sandwich of anode-separator-cathode layers. (b) Direct fabrication of Li-ion battery on the surface of interest by sequentially spraying component paints stencil masks tailored to desired geometry and surface.

plating if accidentally overcharged. Absence of solid electrolyte interface (SEI) formation, stable and longer cycle life due to low volume change during charging and discharging are other advantages in choosing $\mathrm{LTO}^{17}$.

While conductive $\mathrm{Cu}$ paints are commercially available, a conductive $\mathrm{Al}$ paint would require the use of $\mathrm{Al}$ micro-powders, which are dangerous in use (form explosive aerosols) and have a high degree of surface oxidation. So, Al paints were not considered viable. Singlewalled nanotube (SWNT) current collectors have been used in batteries ${ }^{4,18}$ due to their high electrical conductivity and electrochemical stability at potentials above $1 \mathrm{~V} \mathrm{vs} . \mathrm{Li} / \mathrm{Li}^{+}$. We found that high concentrations $(\sim 0.5-1 \% \mathrm{w} / \mathrm{v})$ of SWNTs can be readily dispersed without the use of surfactants ${ }^{19,20}$ or polymeric binders ${ }^{21,22}$ by bath ultrasonication in 1-methyl-2-pyrrolidone (NMP) to form viscous, highly consistent inks suitable for spray painting. We chose NMP due to its ability to solvate pristine SWNTs without altering its electronic properties or requiring any post-treatments such as surfactant removal ${ }^{23}$. A $20 \% \mathrm{w} / \mathrm{w}$ of Super $\mathrm{P}^{\mathrm{TM}}$ (SP) conductive carbon additive lowers the sheet resistance of the spray-painted SWNT films $\left(\sim 2 \mathrm{mg} / \mathrm{cm}^{2}\right)$ up to $10 \Omega / \square$, sufficient for use as current collectors.

LCO paint was made by adding a mixture of LCO, SP carbon and ultrafine graphite (UFG) into Polyvinylidine fluoride (PVDF) binder solution in NMP. Spray painted electrodes with only SP carbon as conductive additive had poor capacity retention, possibly due to inhomogeneous distribution of the small SP carbon particles $(\sim 50 \mathrm{~nm})$ in films composed of far larger LCO particles (7-10 $\mu \mathrm{m})$. Addition of UFG (particle size $\leq 5 \mu \mathrm{m}$, comparable to LCO) gave more homogeneous distribution of conducting pathways, improving capacity retention ${ }^{24}$ (details in supplementary information, section SI-1 and Fig. S1).

In Li-ion polymer batteries, well-controlled microporosity of polymer separators is crucial for optimal electrolyte uptake and formation of a microporous gel electrolyte (MGE) with high ionic conductivity, which is necessary for complete capacity utilization and its retention upon cycling ${ }^{25,26}$. Thus, obtaining the right morphology in a spray-painted separator was considered the most crucial step for realization of a paintable Li-ion battery. Besides, adhesion of the separator to various substrates is key to making the paintable battery mechanically robust. We could obtain microporous separators with good adhesion characteristics from a paint prepared by blending Kynarflex®-2801 (Kynarflex) polymer with poly(methyl methacrylate) (PMMA) and fumed $\mathrm{SiO}_{2}$ (27:9:4 ratio by wt.) in a $8: 1$ (by vol.) mixture of acetone and N,N-Dimethylformamide (DMF). Kynarflex was used due to its good solubility in low boiling solvents and electrochemical stability in a wide voltage window ${ }^{27}$, while PMMA was used to promote adhesion to a variety of substrates. Kynarflex-PMMA separators fabricated from paints in acetone had good adhesion, but had a fibrous morphology with very high porosity and excessive electrolyte uptake which made them mechanically unstable. We found that by adding DMF to the paint, the microporosity and electrolyte uptake could be tailored to make the separators mechanically robust upon electrolyte addition. This,
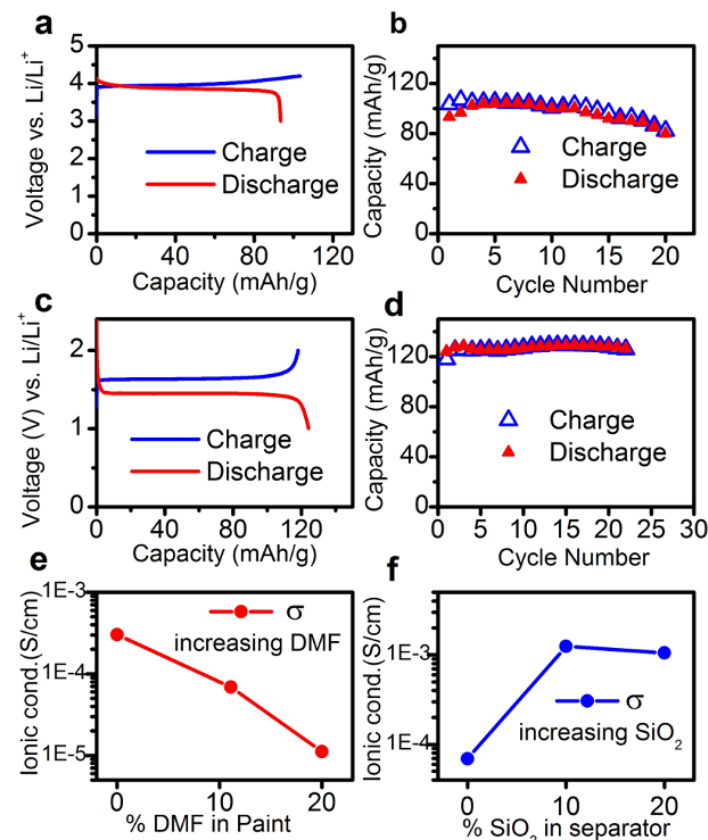

Cycle Number
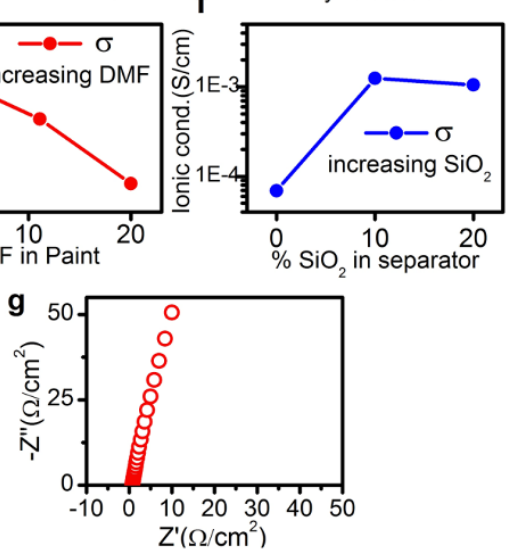

Figure $2 \mid$ Electrochemical characterization of individual components of paintable Li-ion battery. Composite electrodes: Charge-discharge curves and specific capacity vs. cycle numbers for spray painted (a,b), LCO/MGE/ Li half-cell cycled between $4.2-3 \mathrm{~V}$ vs. $\mathrm{Li} / \mathrm{Li}^{+}$at $\mathrm{C} / 8$ and (c, d), LTO/MGE/ $\mathrm{Li}$ half-cell cycled between $2-1 \mathrm{~V}$ vs. $\mathrm{Li} / \mathrm{Li}^{+}$at $\mathrm{C} / 5$. Both half cells show desired plateau potentials and good capacity retention. Polymer separator optimization: (e) Addition of DMF to polymer paint gave a mechanically robust separator but drastically reduced ionic conductivity. (f) Addition of $\mathrm{SiO}_{2}$ (at $\sim 11 \%$ DMF) helped recover the ionic conductivity while maintaining mechanical robustness. Ionic conductivities were calculated from impedance spectra in supplementary Fig. S4. (g) High frequency region of electrochemical impedance spectrum of a typical optimized polymer measured at $23^{\circ} \mathrm{C}$. The separator shows low ionic resistance, with ionic conductivity $\sim 1.24 \times 10^{-3} \mathrm{~S} / \mathrm{cm}$. 
however, also reduced the ionic conductivity of MGE by a factor of $\sim 4$ at $11 \%$ DMF content (Fig. 2e). A further addition of $10 \% \mathrm{w} / \mathrm{w}$ fumed $\mathrm{SiO}_{2}$ to the separator helped offset this loss in conductivity and gave the best compromise between mechanical stability, porosity and ionic conductivity (Fig. $2 \mathrm{f}-\mathrm{g}$ ) (details on optimization of polymer separator in supplementary information, section SI-2 and Figs. S2-S4).

Before assembling the Li-ion cell, spray painted LCO/Polymer and LTO/Polymer stacks were tested in half cell configuration to ensure that both electrodes were performing optimally with the optimized MGE. Galvanostatic charge-discharge curves of both half-cells displayed expected plateau potentials $\left(\sim 3.91 \mathrm{~V}^{28}\right.$ for $\mathrm{LCO}$ and $\sim 1.5 \mathrm{~V}$ for $\left.\mathrm{LTO}^{16}\right)$, good initial capacities $(\sim 100 \mathrm{mAh} / \mathrm{g}$ for LCO, $\sim 125 \mathrm{mAh} / \mathrm{g}$ for LTO) and good capacity retention upon cycling (Fig. 2a-d).

$\mathrm{Li}$-ion cells were fabricated by spraying component paints with an airbrush onto desired substrates (Supplementary Movie-S1). We started the assembly with the cathode CC, but the painting sequence can be easily reversed. Non-conducting substrates (glass, ceramics and polymer sheets) were preheated to $120^{\circ} \mathrm{C}$ and the SWNT paint was sprayed onto them to deposit SWNT films $\left(\sim 2 \mathrm{mg} / \mathrm{cm}^{2}\right.$, $\left.\mathrm{R}_{\mathrm{s}} \sim 10 \Omega / \square\right)$. The LCO paint was then sprayed on top of the SWNT CC to deposit the LCO electrode $\left(\sim 15 \mathrm{mg} / \mathrm{cm}^{2}\right.$ of LCO). After drying, the separator was deposited by spraying polymer paint onto the electrode preheated to $105^{\circ} \mathrm{C}\left(\sim \mathrm{T}_{\mathrm{g}}\right.$ of PMMA). While spraying, it was necessary to deposit the first few coats slowly and allow them to dry to create an interfacial adhesion layer. Without this step, the separator peeled off the substrate. Subsequent coats of polymer paint were then applied up to a final thickness of $\sim 200 \mu \mathrm{m}$. The thick separators prevented internal shorting due to solvent penetration while depositing the top electrode. Then, the LTO paint was slowly spray painted onto the separator preheated to $\sim 95^{\circ} \mathrm{C}$ to deposit the LTO electrode $\left(\sim 10 \mathrm{mg} / \mathrm{cm}^{2}\right)$. For each layer, calibrated volumes of paints were sprayed to achieve required weight or thickness. Lastly, commercially available conductive $\mathrm{Cu}$ paint was sprayed onto the LTO electrode to serve as the anode CC. The cell was vacuum dried, transferred to an Argon filled glove box and after soaking in electrolyte, the finished cell was packaged with laminated poly(ethylene)-aluminum-poly(ethylene terephthalate) (PEAl-PET) sheets (see supplementary information, section SI-3 and Fig. S5).

Cross-sectional SEM micrograph of a spray painted Li-ion cell (Fig. 3c) shows component layers with reasonably uniform thickness and well-formed interfaces. Galvanostatic charge-discharge curves of a similar Li-ion cell (Fig. $3 \mathrm{~d})$ showed plateau potentials $(\sim 2.4 \mathrm{~V}$ for charge and $\sim 2.3 \mathrm{~V}$ for discharge) and discharge capacity ( $\sim 120 \mathrm{mAh}$ per $\mathrm{g}$ of LTO) expected for the LTO-LCO electrode combination. The cell retained $90 \%$ of its capacity after 60 cycles with $>98 \%$ columbic efficiency (Fig. 3e), suggesting that all components were working efficiently upon integration, without degradation or delamination of the cell stack.
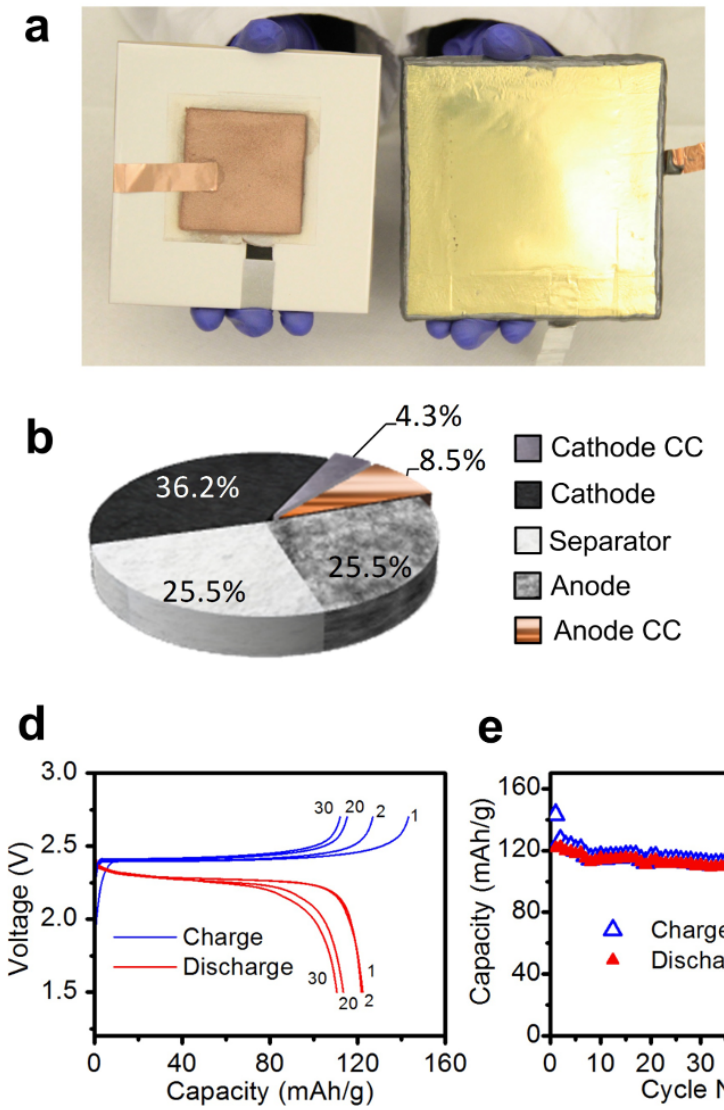

e

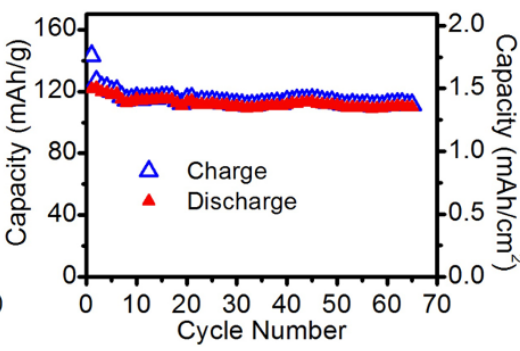

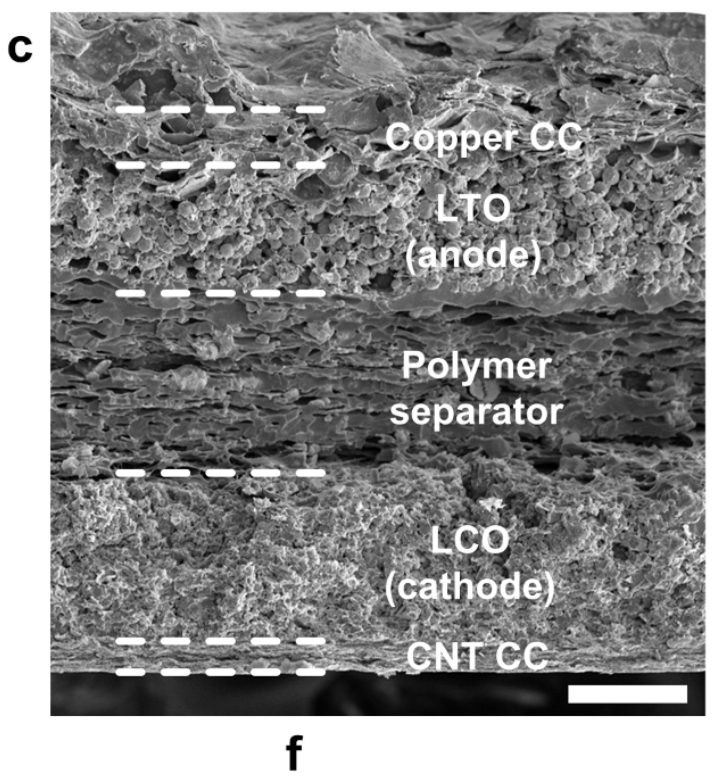

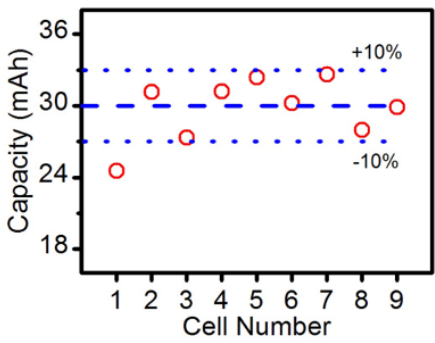

Figure 3 Characterization of spray painted Li-ion cells. (a) (Left) Glazed ceramic tile with spray painted Li-ion cell (area $5 \times 5 \mathrm{~cm}^{2}$, capacity $\sim 30 \mathrm{mAh}$ ) shown before packaging. (Right) Similar cell packaged with laminated PE-Al-PET sheets after electrolyte addition and heat sealing inside glove box. (b) Mass distribution of components in a typical painted battery. (c) Cross-sectional SEM micrograph of a spray painted full cell showing its multilayered structure, with interfaces between successive layers indicated by dashed lines for clarity (Scale bar is $100 \mu \mathrm{m})$. (d) Charge-discharge curves for $1^{\text {st }}, 2^{\text {nd }}, 20^{\text {th }}$ and $30^{\text {th }}$ cycles and (e) Specific capacity vs. cycle numbers for the spray painted full cell (LCO/MGE/LTO) cycled at a rate of C/8 between $2.7-1.5 \mathrm{~V}$. (f) Capacities of 8 out of 9 cells fall within $10 \%$ of the targeted capacity of $30 \mathrm{mAh}$, suggesting good process control over a complex device even with manual spray painting. 


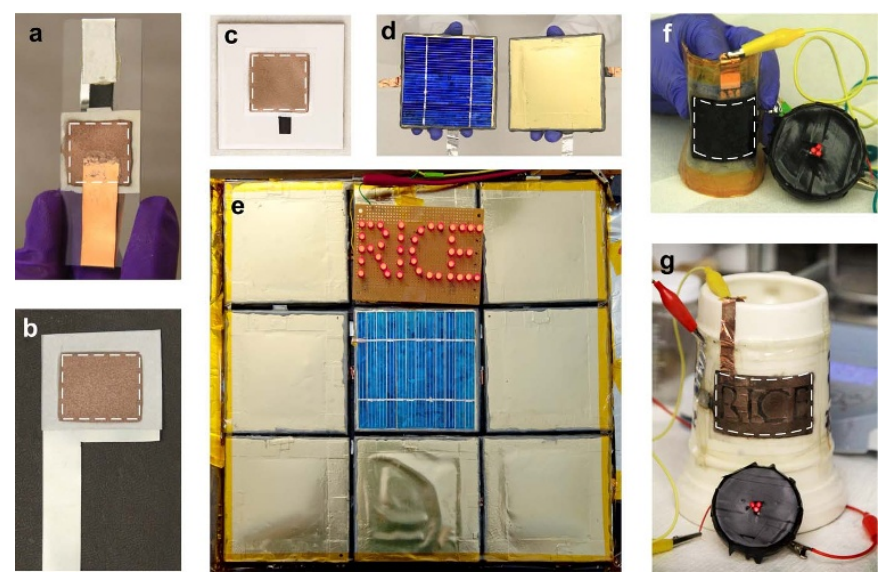

Figure $4 \mid$ Demonstrations of paintable battery. Li-ion cell fabricated on (a), glass slide; (b) stainless steel sheet; (c) glazed ceramic tile. (d) (Left) A packaged and charged tile cell and (right) a similar tile cell charged with a photovoltaic panel mounted on the tile. (e) Fully charged battery of 9 parallely connected powering 40 red LEDs spelling 'RICE'. (f) A flexible spray-painted Li-ion cell fabricated on a PET transparency sheet, powering LEDs. (g) Spray painted Li-ion cell fabricated on the curved surface of a ceramic mug, powering LEDs. The top electrode (LTO/Cu) was sprayed through a stencil mask to spell 'RICE'. The cell area in a, b, c, f and $g$ has been highlighted by dashed line for clarity.

\section{Discussion}

Spray painting is a versatile process for battery fabrication. To demonstrate this, we fabricated batteries on a wide variety of engineering materials such as glass, stainless steel, glazed ceramic tiles and flexible polymer sheets without any surface conditioning (Fig. $4 \mathrm{a}-\mathrm{c}, 4 \mathrm{f}$ ). We observed no effect of these substrate types on performance of batteries. Further, we fabricated a battery conformally on the curved surface of a ceramic mug by spraying paints through a stencil mask spelling 'RICE' (Fig. 4g), to show the flexibility in surface forms and device geometries accessible using spray painting. More complicated surface geometries could be accessible by using optimal nozzle designs and tailoring the rheological characteristics of paints.

Spray painting is a widely used industrial process and could be used to create a large number of small "lego unit" batteries that could be used to create different configurations for varied applications. We batch fabricated 9 Li-ion cells on ceramic tiles (identical to Fig. 3a). Since the capacities of batteries are decided by the active material weights, we controlled the required amount of active materials by the sprayed volume of cathode and anode paints. The capacity of anode was kept less (anode limited cell) to achieve long cycling life ${ }^{29,30}$. Out of 9 identically fabricated Li-ion cells, 8 had capacities within $\pm 10 \%$ of the targeted capacity (Fig. 3f), suggesting good reproducibility for a relatively complex device even by manual spray painting. In the present study, we have targeted high energy densities but considering the high ionic conductivity of the used gel electrolyte, good interface between component layers and capacity retention over cycling at $\mathrm{C} / 8$ current rate with no visible voltage polarization, we expect LTO-LCO based paintable batteries to perform well at higher rates. The use of SWNT current collector is not expected to affect the rate capability of these cells due to the low interfacial resistance between the cathode and SWCNT current collector ${ }^{31}$.

The 9 fabricated cells were connected in parallel to store a total energy of $\sim 0.65 \mathrm{Wh}$ (Fig. $4 \mathrm{e}$ ), equivalent to $6 \mathrm{Wh} / \mathrm{m}^{2}(\sim 80$ lego units). This 'lego unit' system can also be subsequently integrated with other devices. For example, an array of cheap polycrystalline silicon solar cells was glued on top of one of the finished cells (Fig. 4d) and connected to it through a current limiter circuit. This cell was simply charged by illuminating with white light, while the rest eight cells were charged using a galvanostat. The fully charged battery pack (9 parallel cells) delivered enough energy to power 40 red LEDs for more than $6 \mathrm{~h}$ (at $\sim 40 \mathrm{~mA}$ ) and could be easily reconfigured to supply different voltages and current capacities. Such 'lego' cells, when combined with solar cells, could be used to convert any outdoor surface to an energy conversion-storage device.
In summary, battery materials can be engineered into paint formulations and simple spray painting techniques can be used to fabricate batteries directly on surfaces of various materials and of different shapes. We also integrated a photovoltaic panel with this technology to demonstrate energy capture-storage hybrid devices, which could be integrated into large outdoor surfaces and objects of daily use without constraints of space or form factor. The technique could be applied to virtually any multilayer energy storage or conversion devices such as supercapacitors or paintable solar cells ${ }^{32}$. In the present work, we targeted Li-ion batteries due to their high energy and power density. However, fabrication and conditioning of Li-ion batteries requires use of toxic, flammable and potentially corrosive liquid electrolytes and an oxygen and moisture-free environment. Applying our technique, in its present form, to build Liion batteries directly on outdoor objects could be costly due these stringent requirements. Battery components (electrolyte and electrode) that are less sensitive to moisture and oxygen along with development of moisture and oxygen barrier paints would enable assembly of batteries without use of dry rooms, possibly even by nonspecialists, enabling widespread renewable energy capture, storage and utilization.

\section{Methods}

Preparation of paints. Positive CC paint: A mixture of purified Hipco SWNTs (Rice University) and $20 \% \mathrm{w} / \mathrm{w}$ SP Carbon (Timcal Ltd. Switzerland) was dispersed in NMP by ultrasonication $(5 \mathrm{mg} / \mathrm{ml})$. Cathode paint: A $85: 5: 3$ (by wt.) mixture of LCO (Sigma Aldrich), SP carbon and UFG (UFG-5, Showa Denko America, Inc.) was dispersed in a $4 \% \mathrm{w} / \mathrm{v}$ PVDF $\left(\mathrm{M}_{\mathrm{w}} \sim 534,000\right.$, Sigma Aldrich) binder solution in NMP to a total solid content of $60 \%$ w/v. Polymer separator paint: A $27: 9: 4$ (by wt.) mixture of Kynarflex®-2801 (Arkema Inc.), PMMA $\left(M_{W} \sim 120,000\right.$, Sigma Aldrich) and fumed $\mathrm{SiO}_{2}$ (Cabot Inc.) was dispersed in a binary solvent mixture of Acetone and DMF (8:1 by vol.). Anode paint: A 80:10 (by wt.) mixture of LTO (Pred Materials International Inc.) and UFG was dispersed in a 7\% w/v PVDF binder solution in NMP to a total solid content of $\sim 67 \%$. Negative CC paint: Commercially available copper conductive paint (Casewell Inc.) was diluted with ethanol and used as negative current collector paint. Detailed optimization process of paints has been described in online supplementary information, sections SI-1 and SI-2.

Fabrication of paintable Li-ion batteries. Li-ion batteries were fabricated by sequentially spraying the component paints on desired surface using an airbrush operating at 40 psi of compressed air. The paints can be sprayed through a set of masks made according to desired device geometry. Temperature of substrate was controlled from $90-120^{\circ} \mathrm{C}$ using a heat gun or hot plate. $\mathrm{Cu}$ and $\mathrm{Al}$ metal tabs were attached to the negative and positive current collectors respectively. The finished cell was transferred to argon filled glove box and activated by soaking for at least $2 \mathrm{~h}$ in an electrolyte consisting of $1 \mathrm{M} \mathrm{LiPF}_{6}$ solution in $1: 1(\mathrm{v} / \mathrm{v})$ mixture of ethylene carbonate and dimethyl carbonate (Sigma Aldrich). The cell was packaged by heat sealing with PE-Al-PET (Pack Plus Converting Corp.) laminated sheets and 3 M 615 thermo-bonding films (see supplementary information, section SI-3 and Movie-S1). 
Electrochemical Characterization. Electrochemical impedance spectroscopy (EIS) measurements on polymer separators were performed in a Swagelok ${ }^{\mathrm{TM}}$ cell in SS/ MGE/SS configuration using AUTOLAB PGSTAT 302N station. The measurements were performed over $100 \mathrm{KHz}-1 \mathrm{~Hz}$ frequency range with a $10 \mathrm{mV}$ AC bias. The SS worked as a blocking electrode. Galvanostatic charge-discharge measurements were performed on Arbin Instruments BT-2000 battery cycler. LTO/MGE/Li and LCO/ MGE/Li half-cells were cycled in Swagelok ${ }^{\mathrm{TM}}$ cells at $\mathrm{C} / 5$ and $\mathrm{C} / 8$ current rate, where $\mathrm{C}$ is the current required to fully charge or discharge a cell in $1 \mathrm{~h}$. Fully spray-painted cells were charged at current rate of $\mathrm{C} / 8$. For charging the hybrid energy capturestorage device, an array of crystalline Si solar cells with an output voltage of $\sim 5 \mathrm{~V}$ was connected to a tile cell through a transistor current limiter circuit. The panel was then exposed to a $10 \mathrm{~W}$ CFL lamp and the output current of the circuit was regulated to $\mathrm{C} / 8$. A similar current limiter circuit was used to control the discharge current in the demonstration (Fig. 4e) to around C/6.

1. Linden, D. \& Reddy, T. B. (eds) Handbook of Batteries Ch. 35, $3^{\text {rd }}$ edn (McGrawHill, 2002).

2. Spare, B. L. Design and Construction of Non-Rectangular Batteries. U.S. Patent Publication No. US 2012/0015236 A1.

3. Nishide, H. \& Oyaizu, K. Toward Flexible Batteries. Science 319, 737-738 (2008)

4. Hu, L., Wu, H., La Mantia, F., Yang, Y. \& Cui, Y. Thin, Flexible Secondary Li-Ion Paper Batteries. ACS Nano 4, 5843-5848 (2010).

5. Hu, L. et al. Stretchable, Porous, and Conductive Energy Textiles. Nano Lett. 10 708-714 (2010).

6. Liu, Y., Gorgutsa, S., Santato, C. \& Skorobogatiy, M. Flexible, Solid ElectrolyteBased Lithium Battery Composed of $\mathrm{LiFePO}_{4}$ Cathode and $\mathrm{Li}_{4} \mathrm{Ti}_{5} \mathrm{O}_{12}$ Anode for Applications in Smart Textiles. J. Electrochem. Soc. 159, A349-A356 (2012).

7. Pushparaj, V. L. et al. Flexible energy storage devices based on nanocomposite paper. Proceedings of the National Academy of Sciences 104, 13574-13577 (2007).

8. Jones, S. D. \& Akridge, J. R. A thin-film solid-state microbattery. J. Power Sources 44, 505-513 (1993).

9. Yang, Y. et al. Transparent lithium-ion batteries. Proceedings of the National Academy of Sciences 108, 13013-13018 (2011).

10. Harb, J. N., LaFollette, R. M., Selfridge, R. H. \& Howell, L. L. Microbatteries for self-sustained hybrid micropower supplies. J. Power Sources 104, 46-51 (2002).

11. Leonov, V. \& Vullers, R. J. M. Wearable electronics self-powered by using human body heat: The state of the art and the perspective. Journal of Renewable and Sustainable Energy 1, 062701-062701-14 (2009).

12. Gamota, D. R., Brazis, P., Kalyanasundaram, K. \& Zhang, J. (eds) Printed Organic and Molecular Electronics. (Kluwer Academic Press, Massachusetts, 2004).

13. Megahed, S. \& Ebner, W. Lithium-ion battery for electronic applications. J. Power Sources 54, 155-162 (1995)

14. Tarascon, J.-M. \& Armand, M. Issues and challenges facing rechargeable lithium batteries. Nature 414, 359-367 (2001)

15. Sheng Shui, Z. A review on the separators of liquid electrolyte Li-ion batteries. J. Power Sources 164, 351-364 (2007)

16. Ferg, E., Gummow, R. J., de Kock, A. \& Thackeray, M. M. Spinel Anodes for Lithium-Ion Batteries. J. Electrochem. Soc. 141, L147-L150 (1994).

17. Scrosati, B. \& Garche, J. Lithium batteries: Status, prospects and future. J. Power Sources 195, 2419-2430 (2010).

18. Kiebele, A. \& Gruner, G. Carbon nanotube based battery architecture. Applied Physics Letters 91, 144104-144104-3 (2007).

19. Moore, V. C. et al. Individually Suspended Single-Walled Carbon Nanotubes in Various Surfactants. Nano Lett. 3, 1379-1382 (2003).

20. Islam, M. F., Rojas, E., Bergey, D. M., Johnson, A. T. \& Yodh, A. G. High Weight Fraction Surfactant Solubilization of Single-Wall Carbon Nanotubes in Water. Nano Lett. 3, 269-273 (2003).

21. Tang, B. Z. \& Xu, H. Preparation, Alignment, and Optical Properties of Soluble Poly(phenylacetylene)-Wrapped Carbon Nanotubes. Macromolecules 32, 25692576 (1999)
22. Simmons, T. J., Hashim, D., Vajtai, R. \& Ajayan, P. M. Large Area-Aligned Arrays from Direct Deposition of Single-Wall Carbon Nanotube Inks. J. Am. Chem. Soc. 129, 10088-10089 (2007).

23. Ausman, K. D. et al. Organic solvent dispersion of single-walled carbon nanotubes: Toward solutions of pristine nanotubes. J. Phys. Chem. B 104, 89118915 (2000).

24. Hong, J. K., Lee, J. H. \& Oh, S. M. Effect of carbon additive on electrochemical performance of $\mathrm{LiCoO}_{2}$ composite cathodes. J. Power Sources 111, 90-96 (2002).

25. Li, Z., Su, G., Wang, X. \& Gao, D. Micro-porous P(VDF-HFP)-based polymer electrolyte filled with $\mathrm{Al}_{2} \mathrm{O}_{3}$ nanoparticles. Solid State Ionics 176, 1903-1908 (2005)

26. Boudin, F., Andrieu, X., Jehoulet, C. \& Olsen, I. Microporous PVdF gel for lithium-ion batteries. J. Power Sources 81-82, 804-807 (1999).

27. Tarascon, J.-M., Gozdz, A. S., Schmutz, C., Shokoohi, F. \& Warren, P. C. Performance of Bellcore's plastic rechargeable Li-ion batteries. Solid State Ionics 86-88, 49-54 (1996).

28. Yoon, W.-S. \& Kim, K.-B. Synthesis of $\mathrm{LiCoO}_{2}$ using acrylic acid and its electrochemical properties for Li secondary batteries. J. Power Sources 81-82, 517-523 (1999)

29. Wu, H. M. et al. Development of $\mathrm{LiNi}_{0.5} \mathrm{Mn}_{1.5} \mathrm{O}_{4} / \mathrm{Li}_{4} \mathrm{Ti}_{5} \mathrm{O}_{12}$ system with long cycle life. J. Electrochem. Soc. 156, A1047-A1050 (2009).

30. Song, M-Sang et al. Charge/Discharge property and cycle life of $\mathrm{Li}_{4} \mathrm{Ti}_{5} \mathrm{O}_{12} /$ $\mathrm{LiCoO}_{2}-\mathrm{LiNi}_{1-\mathrm{x}-\mathrm{y}} \mathrm{Co}_{\mathrm{x}} \mathrm{Al}_{\mathrm{y}} \mathrm{O}_{2}$ cell for electricity storage applications:Effect of cell design parameters. Clean Technology ISBN-978-1-4398-3419-0 (2010).

31. Wu, H-Chang, Lee, E., Wu, N-Lih \& Jow, T. R. Effects of current collectors on power performance of $\mathrm{Li}_{4} \mathrm{Ti}_{5} \mathrm{O}_{12}$ anode for Li-ion battery. J Power Sources 197, 301-304 (2012)

32. Genovese, M. P., Lightcap, I. V. \& Kamat, P. V. Sun-Believable Solar Paint. A Transformative One-Step Approach for Designing Nanocrystalline Solar Cells. ACS Nano 6, 865-872 (2011).

\section{Acknowledgments}

NS and PMA acknowledge Advance Energy Consortium for financial support. CG acknowledges funding from national science foundation through the PIRE program. PMA and ALMR also acknowledge Army Research Laboratories for support. AV acknowledges FSR and FRS-FNRS for support. WG acknowledges support from Nanoholdings Inc. We acknowledge Pred Material International Inc., 3 M Corp., Timcal Ltd., Arkema Inc. for providing samples of materials for testing. The authors also thank Dr. Kinson Kam (Lawrence Berkeley National Laboratory), Daniel Hashim and Dr. T. N. Narayanan (Rice University) for valuable inputs.

\section{Author contributions}

NS, AndreaM and CG optimized the polymer separator. NS, AkshayM, CG and WG contributed to optimize CNT inks. NS and WG performed SEM. NS optimized LCO and LTO paints and performed electrochemical measurements. CG and NS fabricated and demonstrated paintable batteries on various substrates. ALMR contributed to discussions of results. NS, CG, AV and PMA wrote the manuscript. All authors discussed the results and commented on the manuscript.

\section{Additional information}

Supplementary information accompanies this paper at http://www.nature.com/ scientificreports

Competing financial interests: The authors declare no competing financial interests.

License: This work is licensed under a Creative Common

Attribution-NonCommercial-NoDerivative Works 3.0 Unported License. To view a copy of this license, visit http://creativecommons.org/licenses/by-nc-nd/3.0/

How to cite this article: Singh, N. et al. Paintable Battery. Sci. Rep. 2, 481; DOI:10.1038/ srep00481 (2012) 